\title{
Interviewing children: the impact of the COVID-19 quarantine on children's changes in routine and psychological distress.
}

\section{Giulia Segre}

Istituto di Ricerche Farmacologiche Mario Negri IRCCS

Rita Campi

Istituto di Ricerche Farmacologiche Mario Negri IRCCS

Francesca Scarpellini

Istituto di Ricerche Farmacologiche Mario Negri IRCCS

Antonio Clavenna

Istituto di Ricerche Farmacologiche Mario Negri IRCCS

Michele Zanetti

Istituto di Ricerche Farmacologiche Mario Negri IRCCS

Massimo Cartabia

Istituto di Ricerche Farmacologiche Mario Negri IRCCS

Maurizio Bonati ( $\triangle$ maurizio.bonati@marionegri.it)

Istituto di Ricerche Farmacologiche Mario Negri IRCCS

\section{Research Article}

Keywords: COVID-19 quarantine, children, psychological distress

Posted Date: August 26th, 2020

DOl: https://doi.org/10.21203/rs.3.rs-64515/v1

License: (c) (i) This work is licensed under a Creative Commons Attribution 4.0 International License. Read Full License 


\section{Abstract}

Background: The COVID-19 outbreak has resulted in governments implementing disease containment measures such as school closures, social distancing, and home quarantine.

To date, only a few studies have drawn attention to the psychological impact of lockdown on Italian children's mental health. The present study aimed to investigate the psychological distress (anxiety and mood symptoms) and changes in routine among Italian primary and middle school students during the COVID-19 quarantine.

Methods: This qualitative interview study was performed between the 18th of May and 7th of June 2020: it involved a sample of 82 children and adolescents living in Milan (Italy), attending primary and middle school (aged 6 to 14 years), and their parents.

Results: Almost $30 \%$ of the subjects reported having struggled to adjust to home learning. 36 responders completely changed their dietary habits during the lockdown: they were not eating the same amount of food and were consuming more junk food. Sleep habits were also affected by the lockdown measures: $28 \%$ of the sample had difficulties sleeping and wished to sleep in their parents' bed. Concerning psychological distress, 64 (78\%) children and adolescents had anxiety symptoms; $43.9 \%$ of the students reported significant mood symptoms.

Conclusions: Children are not indifferent to the dramatic impact of the COVID-19 epidemic: our data confirm their difficulties in adapting to the quarantine measures. The effects of stress exposure may not manifest later on during the children's development, and, for this reason, it would be interesting to follow up on these participants to improve our understanding of how long these outcomes may last.

\section{Background}

In December 2019, the outbreak of a new strain of coronavirus disease occurred in Wuhan, (China) and spread across the world within a short time; the WHO declared the coronavirus disease 2019 (COVID-19) outbreak, caused by severe acute respiratory syndrome coronavirus 2 (SARS-CoV-2), to be a pandemic on March 12, 2020.

This pandemic has resulted in governments implementing disease containment measures such as school closures, social distancing, and home quarantine.

In Lombardy, the most affected Italian region, the first school closure began the 21st of February 2020, and, on 5 March 2020, all schools in Italy were closed and students isolated at home for the rest of the academic year, with schooling shifted to home based distance-learning models. In Italy there is usually a Summer school break: children are on holiday from the beginning of June to the middle of September.

Evidence is emerging that children may be significantly less likely to become infected than adults, and do not appear to be super spreaders. Governments worldwide should allow all children back to school 
regardless of comorbidities. The media highlight of a possible, rare, new Kawasaki- like vasculitis that may or may not be due to SARS- CoV2 does not change the fact that severe COVID-19 is as rare as many other serious infection syndromes in children that do not cause schools to be closed [1].

The COVID-19 quarantine has affected more than 860 million children and adolescents worldwide. Moreover, the lockdown and school closure may have negative consequences on children, affecting their social life, their education, and their mental health. Although the current school closures differ from summer holidays in that learning is expected to continue digitally, the closures are likely to widen the learning gap between children from lower-income and higher-income families [2].

The COVID-19 pandemic may worsen existing mental health problems and lead to more cases among children and adolescents because of the unique combination of uncertainty, anxiety, fear of becoming ill or seeing a loved one become ill, loss of our normal routines, difficulties in maintaining social connection, and economic recession [3].

After the H1N1 and SARS epidemics, post-traumatic stress is estimated to be four times higher in children who have been in quarantine compared to those who have not, and their likelihood of presenting acute stress disorder, adjustment disorder, and grief is also higher [4].

A recent review highlighted that children and adolescents are probably more likely to experience high rates of depression and anxiety during and after enforced isolation ends [5]. The authors found a clear association between loneliness and mental health problems, mostly depression, in children and adolescents. Loneliness was associated with future mental health problems up to 9 years later.

These results are consistent with data emerging from China during the COVID-19 pandemic, where children aged 6 to 18 years were more likely to show inattention and persistent inquiry. Clinging, inattention, and irritability were the most severe psychological conditions demonstrated by the children in all age groups [6].

A Chinese survey [7] conducted during COVID-19 directly involved primary school students and reported higher rates of depressive $(22.6 \%)$ and anxiety $(18.9 \%)$ symptoms compared with the prevalence in other surveys.

Italy was the first European country to implement a national lockdown to contain the spread of severe coronavirus disease 19 (COVID-19) and related strict domestic quarantine policies.

To date, only a few studies [8-10] have drawn attention to the psychological impact of lockdown on Italian children's mental health.

A recent study has examined the psychological effects of the quarantine in youth from Italy and Spain. Data were collected through a survey completed by parents and found that their children had different symptoms such as: difficulty concentrating $(76.6 \%)$, boredom $(52 \%)$, irritability (39\%), restlessness $(38.8 \%)$, nervousness (38\%), feelings of loneliness (31.3\%), uneasiness (30.4\%), and worries $(30.1 \%)$. 
Moreover, the results show that children of both countries used monitors more frequently, spent less time doing physical activity, and slept more hours during the quarantine [8].

The findings of an online survey [9], completed by parents of 2 to 14 year old children, showed that factors such as living in an area more at-risk for contagion or being in closer contact with the virus' effects, do not relevantly affect parents' and children's well-being. Similarly, the quality of the environment, such as the physical characteristics of the living space, is not associated with parents' and children's psychological symptoms. It was the parents' individual perception of the situation, however, and, more specifically, how much they found it difficult to deal with the many strains the quarantine imposes, that was significantly associated with parents' stress and children's psychological problems, and that indirectly impacts on children's behavioural and emotional problems.

One in four children (26.5\%) showed the regressive symptom of the demand for physical proximity to their parents during the night, and almost one in five (18.2\%) manifested fears that they had never had before. Half of the children (53.5\%) showed increased irritability, intolerance to rules, whims and excessive demands, and one in five presented mood changes (21.2\%) and sleep problems, including difficulty in falling asleep, agitation, and frequent waking up (20\%). One in three (34.3\%) displayed nervousness about the topic of the pandemic when it was mentioned at home or on TV. Almost one in three (31.4\%) seemed more calm and one in two (49.6\%) seemed more wise and more thoughtful. Almost all (92.6\%) seemed able to adapt to the pandemic restrictions, although one in two (43.3\%) seemed more listless to the activities they used to perform before the pandemic, including playing, studying, and gaming [10].

Students are facing very different experiences with home learning. School closure is almost certain to increase educational inequalities. In particular, many parents of both primary and secondary school students report struggling with supporting home learning [11].

The social distancing and stay-at-home orders issued in cities across the globe obviously reduce the opportunities for physical activity among children, particularly for children in urban areas living in small apartments. Isolation and shielding could result in increased sedentary behaviours and food consumption, which are likely to impact weight and consequently health and sleep over time [12,13].

During the pandemic, prevalence of physically inactive students increased extensively, from $21.3 \%$ to $65.6 \%$. Overall screen time increased considerably during the pandemic and screen time during leisure was also prolonged, indicating that nearly a quarter of students engaged in long screen time for leisure [7].

To date, the majority of knowledge available from research related to the health needs and experiences of young children has been based on the perspectives of parents and/or paediatric health professionals. A growing number of researchers in the health care field have begun to capture the perspectives of children through qualitative interviews $[14,15]$. 
For this reason, we decided to directly involve children and adolescents with video-interviews to convey their experiences and to more fully understand their needs.

To our knowledge, this is the first study that directly investigates the effects of the COVID-19 lockdown on children's and adolescents' changes in routine and mental health from their own perspective. In particular, the added value of the study is the fact that it directly involved students with video-interviews, letting them share their needs and opinions.

The present study aims to analyse the impact of the quarantine on students' life in Milan, one of the Italian cities most affected by COVID-19. In particular, we focused our attention on changes in routine during the lockdown: distance learning, eating and sleeping habits. Psychological distress such as anxiety and mood symptoms, disease concern, and fears were examined.

\section{Methods}

This qualitative interview study was performed between the 18th of May and 7th of June 2020, for a total of 3 weeks. $18^{\text {th }}$ of May was a meaningful date in Italy: it corresponded to the beginning of the second phase of the lockdown. From May $18^{\text {th }}$ shops reopened (as well as cafès and restaurants) and people were allowed to go outside without the previously required form justifying their reasons, and meeting up with friends was permitted. During this period students were still attending their online classes.

This study involved a representative sample of 82 primary and middle school students (we were able to collect data from across all eight school year levels) living in Milan (Lombardy, Italy). Participants were recruited via different channels (newsletter, website, and social networks) of the Laboratory for Mother and Child health of the Mario Negri Institute in Milan.

This study followed the criteria for reporting qualitative research (COREQ, additional file 1). The ethics committee of the Besta Neurological Institute in Milan approved the study protocol (Report number 73). According to the Italian laws and good ethical practice, a written and informed consent of the parents was required via email before participation in the study. The invitation included an information leaflet explaining the nature of the interviews, who would be present and what to expect, making it clear that participants could stop the interview at any time and the link to connect at the scheduled date, and time of the video-interview. Moreover, before the interview we introduced the aims of the study to the interviewed youth and asked them consent to be involved in the present study.

Before conducting the interviews with study participants, a pilot study was conducted to test the interview design with four students (two males and two females of different grades): at the end participants were asked whether the questions were clear and made them comfortable.

The interviews were conducted by two psychologists (GS and FS, Doctors of Clinical and Psychology) and were about 10 to 20 minutes in duration for each student; respondents' answers where recorded by 
researchers on a questionnaire form (ad hoc created) during the interviews. Students and their parents were at home during the interviews, conducted with a video-meeting platform (Zoom).

Scientific literature related to the psychological impact of quarantine was reviewed and ad-hoc interviews were created in order to investigate changes in routine of children and adolescents and psychological reactions due to the coronavirus lockdown.

The interview (see "additional file 1") was made up of different parts:

The parent was involved at the beginning of the interview in order to introduce the child and reply to a few quick questions: COVID-19 cases within family context, developmental disorders of the child (such as specific learning disorder/special educational needs), residency, and type of school attended by the child (private/state school).

The child directly responded to the main part of the interview, which investigated:

Socio-demographic variables such as age, gender, school grade, house and family situation (information on people living with the respondent during the lockdown), and average screen time per day.

\section{Changes in routine during the lockdown}

- Three questions compared distance learning with normal schooling, and concerned: a) difficulty in maintaining attention during online lessons; b) students' tiredness and fatigue; and c) their motivation and commitment to remote schooling.

For those who responded positively to all the above questions, adjustment to online schooling was a real struggle.

- The interviews investigated the perceived eating habits during quarantine: quantity and quality of food consumption. We focused on those subjects who were not eating the same as before and reported an increase in junk food and sweets.

- Concerning sleeping habits, we analysed whether there had been changes in sleep patterns or the child/adolescent was sleeping the same as before. If there had been changes we asked if they were related to difficulties in falling asleep or waking up many times during the night, or with having more nightmares than usual. Moreover, we also asked the responder if during the quarantine he or she had wished to sleep in his parents' bed.

\section{Emotional and behavioural changes}

Six items were adapted from the anxiety clinical scale of the "Trauma and symptom checklist for children" [16]. A 4-point Likert-type scale was employed to measure the anxiety level: 0 "never", 1 "sometimes", 2 "lots of times", 3 "almost all the time". We divided the scores into 3 main categories: 
normal anxiety (0-9), mild to moderate anxiety (10-14), and severe anxiety (15-18): a subject scored positive for anxiety if the total score was $\geq 10$.

Concerning mood symptoms, we created six ad hoc questions in order to investigate whether during the quarantine there had been changes regarding: loss of interest in doing things, difficulty in focusing, mood swings, tiredness, aggressiveness, frequency in crying. Possible answers were 1 "yes" and 2 "no", with a total score ranging from 0 to 6 . Mood symptoms were considered clinically significant if the total score was $\geq 4$.

\section{Future perspectives}

We also decided to draw the attention to things children missed the most during the lockdown and things they looked forward to doing when everything went back to normal.

\section{Statistical analyses:}

Data are reported as number and percentage of responders. Data analysis was performed using frequency distributions for categorical variables summarized using proportions and associations tested using chi-square or Fisher's exact test where applicable. Continuous variables were summarized using means, standard deviations, and median.

To identify factors influencing psychological distress (anxiety and mood symptoms) we computed odd ratios (OR) considering the significance of the confidence intervals $(\mathrm{Cl})$.

Statistical significance was evaluated using a $95 \%$ confidence interval and a two-tailed $p$-value of $<0.05$. SAS software, version 9.4 (SAS, Institute Inc., Cary, NC, USA) was used for all statistical analyses

\section{Results}

\subsection{Socio-demographic characteristics of the sample}

In total 82 children and adolescents, aged 6 to 14 (mean age of 10.4 years) were interviewed; of whom $53.7 \%$ were males and $46.3 \%$ were females.

Just over half of students (54.9\%) went to primary school and $45.1 \%$ to middle school. Most $(72 \%)$ were attending public schools.

All students were living in Milan (Italy). In particular, 53 (64.6\%) were living in the urban area of Milan, while $29(35.4 \%)$ in the metropolitan area. A minority of the students $(11 \%)$ had specific learning disorders or special educational needs. Most $(89 \%)$ had brothers or sisters; the majority of them $(78 \%)$ had parents who were working during the lockdown. $68.3 \%$ of the subjects spent less than 2 hours per day on leisure screen time, but 26 respondents (31.7\%) reported spending more than two hours a day in front of screens, excluding hours of online lessons and homework. 
Of the 82 children and adolescents who participated in the study, 3 (3.6 \%) tested positive for COVID-19 and $12(14.6 \%)$ had close relatives who had been infected. This means that 7 respondents had been exposed to COVID-19 without contracting the disease.

\subsection{Changes in routine:}

Concerning changes in routine during the lockdown we considered different areas:

- Distance learning: 65 respondents (79.3\%) reported that it was more difficult to focus during online lessons, 53 (64.6\%) found it more tiring, and almost half of the children and adolescents (47.3\%) felt less committed to remote schooling. 27 subjects (32.9\%) responded positively to all the questions related to online schooling, meaning that those students struggled to adjust to home learning.

- Eating habits: the perception of changes in eating habits was observed in $63.4 \%$ of the population, mainly in primary school students $(O R=0.38,95 \%$ C.I: $0.152-0.966, p=.04)$. In particular, more than half of the sample (57.3\%) reported eating more during the lockdown, with an increase in consumption of junk food, snacks, and sweets. 36 responders (43.9\%) completely changed their dietary habits during the lockdown: they were not eating the same amount of food and were consuming more junk food.

- Sleeping habits: Sleep habits were also affected by the lockdown measures. 50 respondents (61\%) reported changes in sleep pattern: the majority of them had difficulties in falling asleep and woke up many times during the night. They went to bed later than before, but due to school lessons had to wake up at around the same time in the morning. Moreover, nearly half of the sample (48.8\%) reported that during the quarantine they wished to sleep in their parents' bed. In total 23 children and adolescents (28\%) had difficulties sleeping and wished to sleep their parents' bed.

\subsection{Fears and symptoms:}

The main fear, shared by the $75.6 \%$ of the sample, is the thought that their family members could fall ill with COVID-19. Children and adolescents were more frightened for their family than for themselves; only $18.3 \%$ of the respondents replied that they were mostly terrorized by the idea of being hospitalized. 18 $(22 \%)$ subjects had normal scores of anxiety (Table 1 ), the mean score was 11.56 (2.65 s.d.). 54 scored mild to moderate, and 10 had severe anxiety symptoms: in total $78 \%$ scored positive for anxiety. There were no significant differences in anxiety levels between males and females, nor between primary and middle school students.

In particular, $30.5 \%$ of the responders reported that almost all of the time they felt afraid that something bad might happen and felt afraid of the dark.

\section{Table 1. Characteristics of total responders by anxiety}




\begin{tabular}{|c|c|c|c|c|c|c|c|}
\hline & \multicolumn{4}{|c|}{ Anxiety } & \multirow[t]{2}{*}{ OR } & \multirow{2}{*}{ Cl 95\% } & \multirow[t]{2}{*}{ p-value } \\
\hline & No & $\%$ & Yes & $\%$ & & & \\
\hline \multicolumn{8}{|l|}{ Gender } \\
\hline Male & 11 & 61,1 & 33 & 51,6 & Reference & & \\
\hline Female & 7 & 38,9 & 31 & 48,4 & 1,48 & $0,51-4,29$ & 0,4744 \\
\hline \multicolumn{8}{|l|}{ COVID_family members } \\
\hline Yes & 2 & 11,1 & 10 & 15,6 & 1,481 & $0,29-7,46$ & 0,6341 \\
\hline No & 16 & 88,9 & 54 & 84,4 & Reference & & \\
\hline \multicolumn{8}{|l|}{ Class } \\
\hline Primary & 11 & 61,1 & 34 & 53,1 & Reference & & \\
\hline Middle & 7 & 38,9 & 30 & 46,9 & 1,39 & $0,48-4,03$ & 0,5484 \\
\hline \multicolumn{8}{|l|}{ Type of school } \\
\hline Private & 6 & 33,3 & 17 & 26,6 & 0,723 & $0,23-2,23$ & 0,573 \\
\hline Public & 12 & 66,7 & 47 & 73,4 & Reference & & \\
\hline \multicolumn{8}{|l|}{ Residential area } \\
\hline Milan, urban area & 10 & 55,6 & 43 & 67,2 & Reference & & \\
\hline Milan, metropolitan area & 8 & 44,4 & 21 & 32,8 & 0,61 & $0,21-1,77$ & 0,3641 \\
\hline \multicolumn{8}{|l|}{ Brothers or sisters } \\
\hline Yes & 16 & 88,9 & 57 & 89,1 & 1,018 & $0,19-5,39$ & 0,9833 \\
\hline No & 2 & 11,1 & 7 & 10,9 & Reference & & \\
\hline \multicolumn{8}{|l|}{ Special learning needs } \\
\hline Yes & 3 & 16,7 & 6 & 9,4 & 0,517 & $0,12-2,31$ & 0,3883 \\
\hline No & 15 & 83,3 & 58 & 90,6 & Reference & & \\
\hline \multicolumn{8}{|c|}{ Parents working during quarantine } \\
\hline Yes & 15 & 83,3 & 49 & 76,6 & Reference & & \\
\hline No & 3 & 16,7 & 15 & 23,4 & 1,53 & $0,39-6,01$ & 0,5422 \\
\hline \multicolumn{8}{|l|}{ Screen usage } \\
\hline Less than two hours & 3 & 16,7 & 23 & 35,9 & Reference & & \\
\hline More than two hours & 15 & 83,3 & 41 & 64,1 & 0,36 & $0,09-1,36$ & 0,1316 \\
\hline
\end{tabular}


Remote school, major difficulties

\begin{tabular}{|c|c|c|c|c|c|c|c|}
\hline Yes & 3 & 16,7 & 24 & 37,5 & 3 & $0,79-1,14$ & 0,1078 \\
\hline No & 15 & 83,3 & 40 & 62,5 & Reference & & \\
\hline \multicolumn{8}{|l|}{ Sleeping as normal } \\
\hline Yes & 7 & 38,9 & 25 & 39,1 & Reference & & \\
\hline No & 11 & 61,1 & 39 & 60,9 & 0,99 & $0,34-2,90$ & 0,9894 \\
\hline \multicolumn{8}{|l|}{ Wish to sleep in parent's bed } \\
\hline Yes & 6 & 33,3 & 34 & 53,1 & 2,267 & $0,76-6,78$ & 0,1434 \\
\hline No & 12 & 66,7 & 30 & 46,9 & Reference & & \\
\hline \multicolumn{8}{|c|}{ Children who were sleeping differently and wished to sleep in parent's bed } \\
\hline Yes & 4 & 22,2 & 19 & 29,7 & 1,478 & $0,43-5,07$ & 0,5352 \\
\hline No & 14 & 77,8 & 45 & 70,3 & Reference & & \\
\hline \multicolumn{8}{|l|}{ Eating as normal } \\
\hline Yes & 10 & 55,6 & 20 & 31,3 & Reference & & \\
\hline No & 8 & 44,4 & 44 & 68,8 & 2,75 & $0,94-8,01$ & 0,0637 \\
\hline \multicolumn{8}{|l|}{ Eating the same quality of food } \\
\hline Yes & 10 & 55,6 & 25 & 39,1 & Reference & & \\
\hline No, more junk food and sweets & 8 & 44,4 & 39 & 60,9 & 1,95 & $0,68-5,61$ & 0,2154 \\
\hline \multicolumn{8}{|c|}{ Eating different quantity and quality of food } \\
\hline Yes & 5 & 27,8 & 31 & 48,4 & 2,442 & $0,78-7,65$ & 0,1254 \\
\hline No & 13 & 72,2 & 33 & 51,6 & Reference & & \\
\hline
\end{tabular}

36 responders (43.9\%) had significant mood symptoms (Table 2), the mean score was 3.43 (1.62 s.d.). The higher frequency of mood symptoms was mainly associated with screen usage (OR $=0.35,95 \%$ C.I: $0.13-0.91, p=.03)$ and with changes in dietary habits: in quantity $(O R=4.14,95 \%$ C.I: $1.51-11.35, p$ $=.0057)$, quality $(\mathrm{OR}=3.90,95 \%$ C.I: $1.50-10.12, \mathrm{p}=.0051)$ and both $(\mathrm{OR}=5.67,95 \%$ C.I: $2.18-14.74, \mathrm{p}<$ $.001)$

Table 2. Characteristics of total responders by changes in mood 
Changes in mood

$\begin{array}{lllllll}\text { No } & \% & \begin{array}{l}\text { Yes } \\ \text { (total }\end{array} & \begin{array}{l}\text { (total } \\ \text { score }\end{array} & & \text { Total } \% & \\ \text { score } & & & & \text { Reference } \\ 4 \text { () } & & & & & \end{array}$

OR

$\begin{array}{ll}\mathrm{Cl} & \mathrm{p}- \\ 95 \% & \text { value }\end{array}$

\section{Gender}

$\begin{array}{llllllllll}\text { Male } & 24 & 52,2 & 20 & 55,6 & 44 & 53,7 & \text { Reference } & & \\ \text { Female } & 22 & 47,8 & 16 & 44,4 & 38 & 46,3 & 0,87 & 0,36- & 0,7606\end{array}$

\section{COVID_family members}

$\begin{array}{llllllllll}\text { Yes } & 4 & 8,7 & 8 & 22,2 & 12 & 14,6 & 3,00 & \begin{array}{l}0,82- \\ 10,92\end{array} & 0,0956\end{array}$

No

42

$91,3 \quad 28$

$77,8 \quad 70$

85,4 Reference

\section{Class}

$\begin{array}{llllllllll}\text { Primary } & 26 & 56,5 & 19 & 52,8 & 45 & 54,9 & \text { Reference } & & \\ \text { Middle } & 20 & 43,5 & 17 & 47,2 & 37 & 45,1 & 1,16 & 0,48- & 0,7353\end{array}$

\section{Type of school}

$\begin{array}{llllllllll}\text { Private } & 12 & 26,1 & 11 & 30,6 & 23 & 28,0 & 1,25 & 0,47- & 0,6551 \\ & & & & & & & 3,28 & \end{array}$

$\begin{array}{llllllll}\text { Public } & 34 & 73,9 & 25 & 69,4 & 59 & 72,0 & \text { Reference }\end{array}$

\section{Residential area}

\begin{tabular}{lcccccccccc}
$\begin{array}{l}\text { Milan, urban } \\
\text { area }\end{array}$ & 27 & 58,7 & 26 & 72,2 & 53 & 64,6 & Reference & \\
$\begin{array}{l}\text { Milan, } \\
\text { metropolitan } \\
\text { area }\end{array}$ & 19 & 41,3 & 10 & 27,8 & 29 & 35,4 & 0,55 & $0,21-$ & 0,206 \\
Brothers or sisters & & & & & & & & & \\
Yes & 40 & 87,0 & 33 & 91,7 & 73 & 89,0 & 1,65 & $0,38-$ & 0,5016 \\
No & 6 & 13,0 & 3 & 8,3 & 9 & 11,0 & Reference & & \\
\hline
\end{tabular}

\section{Special learning needs}




\begin{tabular}{|c|c|c|c|c|c|c|c|c|c|}
\hline Yes & 4 & 8,7 & 5 & 13,9 & 9 & 11,0 & 1,69 & $\begin{array}{l}0,42- \\
6,83\end{array}$ & 0,459 \\
\hline No & 42 & 91,3 & 31 & 86,1 & 73 & 89,0 & Reference & & \\
\hline \multicolumn{10}{|c|}{ Parents working during quarantine } \\
\hline Yes & 37 & 80,4 & 27 & 75,0 & 64 & 78,0 & Reference & & \\
\hline No & 9 & 19,6 & 9 & 25,0 & 18 & 22,0 & 1,37 & $\begin{array}{l}0,48- \\
3,91\end{array}$ & 0,5559 \\
\hline
\end{tabular}

\section{Screen usage}

$\begin{array}{lllllllllll}\begin{array}{l}\text { Less than two } \\ \text { hours }\end{array} & 10 & 21,7 & 16 & 44,4 & 26 & 31,7 & \text { Reference } & \\ \begin{array}{l}\text { More than two } \\ \text { hours }\end{array} & 36 & 78,3 & 20 & 55,6 & 56 & 68,3 & 0,35 & \begin{array}{c}0,13- \\ 0,97\end{array} & 0,0309 \\ \end{array}$

\section{Remote school, major difficulties}

$\begin{array}{llllllllll}\text { Yes } & 14 & 30,4 & 13 & 36,1 & 27 & 32,9 & 1,29 & \begin{array}{l}0,51- \\ 3,26\end{array} & 0,5876\end{array}$

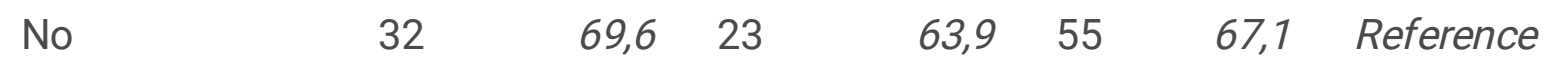

\section{Sleeping as normal}

$\begin{array}{llllllllll}\text { Yes } & 20 & 43,5 & 12 & 33,3 & 32 & 39,0 & \text { Reference } & & \\ \text { No } & 26 & 56,5 & 24 & 66,7 & 50 & 61,0 & 1,54 & 0,62- & 0,3511 \\ & & & & & & & & 3,81 & \end{array}$

Wish to sleep in parent's bed

\begin{tabular}{llllllllll} 
Yes & 22 & 47,8 & 18 & 50,0 & 40 & 48,8 & 1,09 & $0,46-$ & 0,8451 \\
\hline No & 24 & 52,2 & 18 & 50,0 & 42 & 51,2 & Reference &
\end{tabular}

Children who were sleeping differently and wished to sleep in parent's bed

\begin{tabular}{lccccccccc|} 
Yes & 13 & 28,3 & 10 & 27,8 & 23 & 28,0 & 0,98 & $0,37-$ & 0,9615 \\
No & 33 & 71,7 & 26 & 72,2 & 59 & 72,0 & Reference & \\
Eating as normal & & & & & & & & \\
Yes & 23 & 50,0 & 7 & 19,4 & 30 & 36,6 & Reference & \\
No & 23 & 50,0 & 29 & 80,6 & 52 & 63,4 & 4,14 & $1,51-$ & 0,0057 \\
& & & & & & & & 11,35 & \\
\hline
\end{tabular}




\begin{tabular}{|c|c|c|c|c|c|c|c|c|c|}
\hline Yes & 26 & 56,5 & 9 & 25,0 & 35 & 42,7 & Reference & & \\
\hline $\begin{array}{l}\text { No, more junk } \\
\text { food and } \\
\text { sweets }\end{array}$ & 20 & 43,5 & 27 & 75,0 & 47 & 57,3 & 3,90 & $\begin{array}{l}1,50- \\
10,12\end{array}$ & 0,0051 \\
\hline \multicolumn{10}{|c|}{ Eating different quantity and quality of food } \\
\hline Yes & 12 & 26,1 & 24 & 66,7 & 36 & 43,9 & 5,67 & $\begin{array}{l}2,18- \\
14,74\end{array}$ & 0,0004 \\
\hline No & 34 & 73,9 & 12 & 33,3 & 46 & 56,1 & Reference & & \\
\hline
\end{tabular}

Interestingly, nearly three-quarters of the interviewed (73.2\%) reported getting angry more easily than they usually do.

What did children and adolescents miss most during the lockdown?

- $2 \%$ of the sample reported missing their friends a lot

- $72 \%$ of the sample reported missing their hobbies and extracurricular activities (sports or language courses) a lot.

The interviews were concluded with an open question, asking the participants the first things they wanted to do when everything went back to normal. Most of the respondents $(62 \%)$ wanted to meet their school mates or friends again, to start playing their favourite sports again (18.3\%), to be reunited with their families, and to go to the sea.

A feedback on the study's findings was provided to participants and interested people throughout a public national webinar.

\section{Discussion}

This is the first study to directly investigate, from the viewpoint of Italian primary and middle school students, the impact of the COVID-19 quarantine on the changes in their routine and psychological distress. Italy was, after China, the second most highly affected country at the time, with the pandemic spreading very fast around Milan, one of the most involved cities.

Children are not indifferent to the dramatic impact of the COVID-19 epidemic.

For most children and youth the normal routine was disrupted: with the implementation of social distancing interventions, direct human contact became highly restricted, with most activities that typically occupy youths' lives - schooling, extracurricular activities, and socialization with peers - transitioning to electronic-based platforms. 
Routine normally gives the young an increased feeling of safety in the context of uncertainty. Consistent evidence demonstrates that the structured environment of weekdays may help to protect children by regulating obesogenic behaviours, most likely through compulsory physical activity opportunities, restricting caloric intake, reducing screen time occasions, and regulating sleep schedules [17].

For this reason most of the guidelines recommend creating new routines and structures each day to adapt to the pandemic situation.

Our results show that almost half of responders completely changed their dietary habits during the lockdown, eating different amounts of food and consuming more junk food. Sleep habits were also affected by the lockdown measures, with changes in sleep pattern, especially concerning difficulties in falling asleep and waking up many times during the night. Many children and adolescents also wished to sleep in their parents' bed.

The current study strongly supports the hypothesis positing that the COVID-19 pandemic will "exacerbate all of the risk factors for weight gain associated with summer recess" [12]. Specifically, a longitudinal study of children and adolescents with obesity affirmed that eating, activity, and sleep behaviors changed in an unfavorable direction 3 weeks into their confinement during the national lockdown [18]

Are changes in sleep temporary, or will a subset of youth experience longer-term sleep disturbances that originated during the COVID-19 pandemic? Will changes in sleep patterns (such as an increasingly late bedtime in adolescents) result in difficulties once normality starts to return (e.g., when schools reopen and early mornings are required once more) [13]?

Moreover, the reduction of outdoor activities and social interaction may have been associated with an increase in children's emotional and behavioral difficulties. Our findings showed mostly mild to moderate anxiety symptoms, but also significant anxiety in some youth, and nearly half of the responders reported frequent mood swings.

Our results reveal a higher prevalence than that found in another survey conducted in China with primary school students during the Coronavirus-19 outbreak [7].

There is mounting evidence of increased mental health problems during the acute stages of COVID-19. For a subset of children and youth, however, the consequences of pandemic-related stress will not be immediately observable, and will only be detectable following a certain period of development.

Particular attention must be paid to the adaptive behaviour shown by some children that may hide the presence (even if sub-threshold) of depressive symptoms or psychological unease [18].

The effects of stress exposure may not manifest until a certain degree of neurobiological development has occurred or alterations in the social environment lead to change: new difficulties for children who initially appeared well-adapted may surface later in development. The mental health ramifications of COVID- 19 are likely to be longstanding, but not simply chronic [19]. 


\section{Strengths and limitations}

There are several limitations to this study. The sample size was small, but it included wide age range, with full coverage of all the primary and middle school grades.

Socioeconomic details such as household income and number of rooms in the house were not collected, and these data could be helpful in planning future requirements with respect to quarantine.

Another limitation is that our current study could not evaluate whether these outcomes will be longlasting after the COVID-19 outbreak. It will be interesting to continue to follow up with these participants to improve our understanding about how long these outcomes will last.

\section{Implications and future research direction}

The COVID-19 crisis highlights that school fulfils not only an educational mission of knowledge acquisition, but it also satisfies the socialisation needs of young people.

School provides a structured setting in which children can learn and develop social skills, such as selfconfidence, friendship, empathy, participation, respect, gratitude, compassion, and responsibility [20].

Children facing unexpected and unknown events typically exhibit various stress reactions: resilience, the personal attributes that help children manage everything from little disappointments to big life traumas, should be nurtured and implemented by public health programs in children and teens living in areas hit by calamities such as epidemics. If properly supported by healthcare professionals, families, and other social connections, including school environment, children and adolescents can appropriately overcome a condition of distress and prospectively stabilize emotionally and physiologically [6].

\section{Conclusions}

In conclusion, we would like to highlight that children with pre-existing mental and physical disability are at utmost risk given the current situation. The challenges of online learning coupled with a lack of recreational activities that can be done at home can prove to be frustrating for children with physical disabilities. It becomes even more important to keep children with physical and mental disability not only physically safe, but also look after their psychological and emotional wellbeing. In particular, social distancing and its effects are extremely novel and difficult to understand for children, especially those experiencing developmental and intellectual delays. This affects their wellbeing and places them at a higher risk for clinically significant mental health issues [21].

\section{Declarations}

Ethics approval and consent to participate: The authors assert that all procedures contributing to this work comply with the ethical standards of the relevant national and institutional guidelines on care and clinical research. This study has been conducted in accordance with the Helsinky Declaration and the 
procol has been approved by the ethics committee of the Besta Neurological Institute in Milan (Reference number 73). Informed consent to participate in the study was obtained (written, via email) from parents and from their children before the beginning of the interviews.

Consent to publication: Not applicable

Availability of data and materials: The datasets used and/or analyzed during the current study are available from the corresponding author on reasonable request.

Competing interests: All authors declare that they have no conflicts of interest.

Funding: This research received no specific grant from any funding agency in the public, commercial or not-for-profit sectors. The study had no sponsor, so expenses incurred for study design, data collection, data analysis, data interpretation, and writing of the report were paid for by the department funds. The corresponding author had full access to all the data in the study and had final responsibility for the decision to submit for publication.

Authors' contributions: GS, MB, FS and AC designed the study and the interview's questions; GS and FS contacted the families and conducted the interviews. RC, MC and MZ conducted the data analysis. GS and $\mathrm{MB}$ interpreted the data and drafted the article. All authors critically revised the article and reviewed the final draft of the article. MB is the guarantor.

Acknowledgments: The co-operation of the participating students and their families is gratefully acknowledged. The authors would like to acknowledge Chiara Pandolfini for language editing and Daniela Miglio for editing.

\section{References}

1. Munro APS, Faust SN. Children are not COVID-19 super spreaders: time to go back to school. Arch Dis Child 2020;105(7):618-619. doi:10.1136/archdischild-2020-319474.

2. Van Lancker W, Parolin Z. COVID-19, school closures, and child poverty: a social crisis in the making. Lancet Public Health 2020;5(5):e243-e244. doi:10.1016/S2468-2667(20)30084-0.

3. Golberstein E, Wen H, Miller BF. Coronavirus Disease 2019 (COVID-19) and Mental Health for Children and Adolescents. JAMA Pediatr 2020;10.1001/jamapediatrics.2020.1456. doi:10.1001/jamapediatrics.2020.1456.

4. Sprang G, Silman M. Posttraumatic stress disorder in parents and youth after health-related disasters. Disaster Med Public Health Prep 2013;7(1):105-10. doi:10.1017/dmp.2013.22.

5. Loades ME, Chatburn E, Higson-Sweeney N, et al. Rapid Systematic Review: The Impact of Social Isolation and Loneliness on the Mental Health of Children and Adolescents in the Context of COVID19. J Am Acad Child Adolesc Psychiatry 2020;S0890-8567(20)30337-3. doi:10.1016/j.jaac.2020.05.009. 
6. Jiao WY, Wang LN, Liu J, et al. Behavioral and Emotional Disorders in Children during the COVID-19 Epidemic. J Pediatr 2020;221:264-6.e1. doi:10.1016/j.jpeds.2020.03.013.

7. Xie X, Xue Q, Zhou Y, et al. Mental Health Status Among Children in Home Confinement During the Coronavirus Disease 2019 Outbreak in Hubei Province, China. JAMA Pediatr 2020;e201619. doi:10.1001/jamapediatrics.2020.1619.

8. Orgilés M, Morales A, Delveccio E, et al. Immediate Psychological Effects of COVID-19 Quarantine in Youth from Italy and Spain. Preprints, doi: 10.31234/osf.io/qaz9w.

9. Spinelli M, Lionetti F, Pastore M, Fasolo M. Parents' Stress and Children's Psychological Problems in Families Facing the COVID-19 Outbreak in Italy. Front Psychol 2020;11. 10.3389/fpsyg.2020.01713. doi.org/10.3389/fpsyg.2020.01713

10. Pisano L, Galimi D, Cerniglia L. A qualitative report on exploratory data on the possible emotional/behavioral correlates of Covid-19 lockdown in 4-10 years children in Italy. 2020;10.31234/osf.io/stwbn.

11. Andrew A, Cattan S, Costa-Dias M, et al. Learning during the lockdown: real-time data on children's experiences during home learning. IFS Briefing Note BN288. The Institute for Fiscal Studies. ISBN 978-1-912805-78-5.

12. Rundle AG, Park Y, Herbstman JB, Kinsey EW, Wang YC. COVID-19-Related School Closings and Risk of Weight Gain Among Children. Obesity (Silver Spring) 2020;28(6):1008-9. doi:10.1002/oby.22813.

13. Becker SP, Gregory AM. Editorial Perspective: Perils and promise for child and adolescent sleep and associated psychopathology during the COVID-19 pandemic. J Child Psychol Psychiatry 2020;61(7):757-9. doi:10.1111/jcpp.13278.

14. Saurabh K, Ranjan S. Compliance and Psychological Impact of Quarantine in Children and Adolescents due to Covid-19 Pandemic. Indian J Pediatr 2020;87(7):532-6. doi:10.1007/s12098-02003347-3.

15. Ponizovsky-Bergelson Y, Dayan Y, Wahle N, Roer-Strier D. A Qualitative Interview with young children: what encourages or inhibits young children's participation? Int J Qual Methods 2019;

18.160940691984051. doi: 10.1177/1609406919840516.

16. Briere J. Trauma Symptom Checklist for Children: Professional Manual. Odessa, FL: Psychological Assessment Resources, Inc, 1996.

17. Brazendale K, Beets MW, Weaver RG, et al. Understanding differences between summer vs. school obesogenic behaviors of children: the structured days hypothesis. Int J Behav Nutr Phys Act 2017;14(1):100. Published 2017 Jul 26. doi:10.1186/s12966-017-0555-2.

18. Pietrobelli A, Pecoraro L, Ferruzzi A, et al. Effects of COVID-19 Lockdown on Lifestyle Behaviors in Children with Obesity Living in Verona, Italy: A Longitudinal Study. Obesity (Silver Spring) 2020;10.1002/oby.22861. doi:10.1002/oby.22861.

19. Wade M, Prime H, Browne DT. Why we need longitudinal mental health research with children and youth during (and after) the COVID-19 pandemic [published online ahead of print, 2020 May 28]. Psychiatry Res 2020;290:113143. doi:10.1016/j.psychres.2020.113143. 
20. Colao A, Piscitelli P, Pulimeno M, Colazzo S, Miani A, Giannini S. Rethinking the role of the school after COVID-19. Lancet Public Health 2020;5(7):e370. doi:10.1016/S2468-2667(20)30124-9.

21. Patel K. Mental health implications of COVID-19 on children with disabilities. Asian J Psychiatr 2020;54:102273. doi:10.1016/j.ajp.2020.102273.

\section{Supplementary Files}

This is a list of supplementary files associated with this preprint. Click to download.

- additionalfile1.pdf

- additionalfile2.docx 